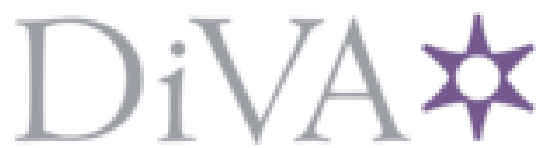

http://www.diva-portal.org

This is the published version of a paper presented at Antennas: Gateways to the Global Network.

Citation for the original published paper:

Beckman, C., Christian, B., Engblom, G. (1998)

Antenna diversity for mobile telephones

In: IEEE Antennas and Propagation Society (ed.), IEEE Antennas and Propagation Society International Symposium. 1998 Digest. Antennas: Gateways to the Global Network. Held in conjunction with: USNC/URSI National Radio Science Meeting (Cat. No.98CH36, Atlanta, GA, 1998, pp. 2220-2223 vol.4. (pp. 2220-2223).

N.B. When citing this work, cite the original published paper.

Permanent link to this version:

http://urn.kb.se/resolve?urn=urn:nbn:se:kth:diva-240130 


\title{
Antenna Diversity for Mobile Telephones
}

\author{
Christian Braun*, Gunnar Engblom and Claes Beckman
}

Allgon Mobile Communication AB, Box 500, 18425 Ákersberga, Sweden

Introduction: Mobile telephones are often used in cities and other urban areas. The signal from a receiving antenna in these environments may experience deep fades that are difficult to avoid. These fades are due to the radio waves propagating in multiple paths on the way from transmitter to receiver. In a worst-case scenario, the waves cancel out almost completely at the point where the receiver is located, and the signal is lost.

Modern cellular communication systerns, such as the GSM system, are designed to combat these fades. Several techniques are used, one of them being antenna diversity. This method is based upon the principle of using two or more antennas in order to receive uncorrelated radio signal. By doing this, there is a possibility of combining the antenna outputs so that a large part of the fading can be avoided [1].

Antenna diversity has so far primarily been used at basestations due to the complexity of the technique and the size limitations on the mobile telephone [2]. However, the Pacific Digital Communication system (PDC) has already implemented the technique in the mobile telephone. Though, in European and American systems antenna diversity in the handset is still to be introduced.

Recently, there has been several studies made on new diversity antennas for the mobile telephone $[3,4]$. The main idea has been to have a built-in (planar) antenna working together with the conventional external. The purpose of this paper is to examine the concept of diversity further and to design two different concepts, one with two external antennas and one with an external antenna combined with an in-built. For evaluation a MATLAB program developed by the Center for Personkommunikation, CPK, in Aaltorg. Denmark, is used. Given the radiation pattern from each antenna and the incoming field distribution from the environnent, this program calculates the diversity performance of the system assuming that selection combining is used to combine the signals[1].

Theory: There are in general three types of antenna diversity that may create uncorrelated signals [1]: space, polarization and angular diversity. When implementing antenna diversity on a handset in the presence of a head, all three types of antenna diversity will probably act together to make the system work. The antennas are placed so close to each other that the space diversity may have little effect and the polarizations will be disturbed by the presence of the head [3]. If the two antennas have the same polarization the most probable decorrealting factor is then the angle or pattern diversity accomplished through the differences in design between the two antennas.

The correlation between two antenna output signals depends on the complex radiation patterns from the antennas and the distribution of the incoming field [3]. However, if the radiation patterns are made orthogonal, the incoming field will not make much difference on the correlation. Through out this paper we will use the complex correlation factor: 


$$
\rho_{c}=\frac{\operatorname{Cov}\left(V_{0,}, V_{0, j}\right)}{\sqrt{\operatorname{Var}\left(\left|V_{0,}\right|\right) \cdot \operatorname{Var}\left(\left|V_{0,}\right|\right)}}
$$

where $V_{0 i}$ and $V_{0 j}$ denote the open circuit voltages of the two antennas, respectively.

In most studies main attention is given to the scenario where there is no line of sight between the transmitter and the receiver. This situation gives rise to short term or Rayleigh fading since the signal envelopes will become Rayleigh distributed.

Because the user, "statistically speaking", turns in every direction the incoming field can be modeled as being uniformly distributed in the azimuth plane [3]. In the elevation plane measurements have shown that the field is very dominant in an angular sector and that it can be modeled as normal distributed [5]:

$$
P_{\theta . \phi}=A e^{\frac{(\theta-(x / 2-m))}{2 \sigma^{2}}}
$$

Here $m$ is the elevation angle at which the incoming field has its maximum and $\sigma$ is the standard deviation.

The incoming field may also have different power for different polarizations. The Cross Polar Discrimination, XPD, is a measure of the ratio between the mean power in the vertical and the horizontal polarizations.

The Mean Effective Gain, MEG, for an antenna is a measure of its effectiveness and defined as the received power divided by the power a theoretical, isotropic antenna would receive in the same environment.

$$
M E G=\frac{P_{\text {ant }}}{P_{\text {is }}}
$$

Measurements: Two prototype antenna systems were made (Fig. 1.): Prototype 1 consists of two identical monopole antennas on a PCB. Prototype 2 is a monopole and a meander antenna on a PCB. The monopole is resonant at $900 \mathrm{MHz}$. The PCB is inserted in a plastic chassi during the measurements.
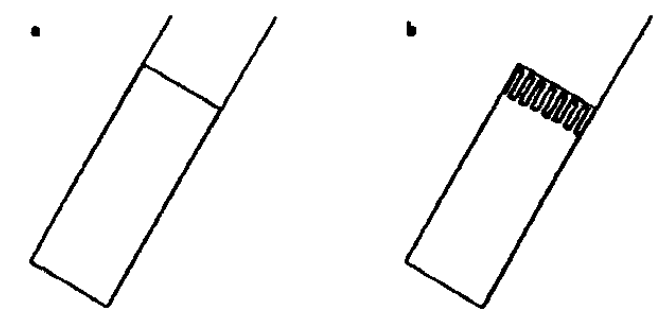

Figurel. Schematic illustrations of a) Prototype 1 and b) Prototype 2.

The 3-dimensional far-field radiation patterns were measured in an ancchoic chamber. During measurements both antennas were connected to matched loads. In order to get results that approximates the real life case, measurements with simulated head and hand were performed. The head was simulated 
with a canister filled with a solution with about the same dielectric properties as the human tissue $(\varepsilon$, of about 50). The hand was simulated with a bag filled with same solution. The canister is somewhat bigger and more square than a human head, but the impression is that it gives reasonabie influence on the radiation pattern.

When the user is talking in the telephone, it is not held vertically. A common standard is that in talk position, the telephone is tilted about 60 degrees from vertical. This is the position used in the measurements.

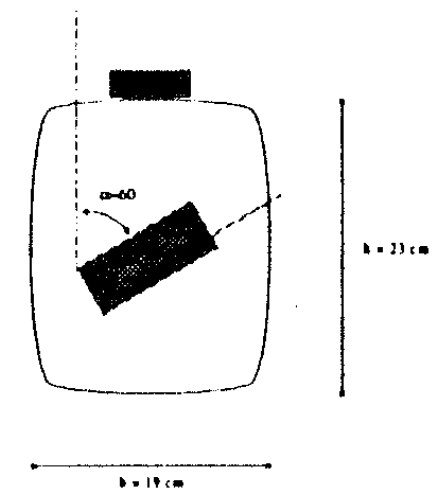

Figure 2. Illustration of the simulated head and terminal during measurements.

Diversity calculations: After measurements of the antenna far field patterns, calculations of the diversity gain was performed using the MATLAB program produced by CPK. Three different cases of radio environment were considered: Outdoor scenario, with $m=10^{\circ}, \sigma=15^{\circ}$ and $\mathrm{XPD}=5 \mathrm{~dB}$; Indoor scenario with $m=20^{\circ}, \sigma=30^{\circ}, \mathrm{XPD}=0 \mathrm{~dB}$; Isotropic scenario, $m=0^{\circ}, \sigma=1000000^{\circ}, \mathrm{XPD}=0 \mathrm{~dB}$. The incoming field are assumed to be Rayleigh distributed and omnidirectional in the horizontal plane. The diversity gain is calculated for selection combining at the $99 \%$ reliability level.

Table I. Results from measurements on prototype I with simulated head.

\begin{tabular}{|l|l|l|l|l|}
\hline & MEG Ant. 1 & MEG Ant. 2 & Correlation & Diversity Gain \\
\hline Urban & $-10.8 \mathrm{~dB}$ & $-12.3 \mathrm{~dB}$ & $0<\left|\rho_{c}\right|^{2}<0.1$ & $\approx 9.3 \mathrm{~dB}$ \\
\hline Indoor & $-12.0 \mathrm{~dB}$ & $-9.7 \mathrm{~dB}$ & $0.1<\left|\rho_{c}\right|^{2}<0.2$ & $\approx 8.8 \mathrm{~dB}$ \\
\hline Isotropic & $-12.3 \mathrm{~dB}$ & $-9.6 \mathrm{~dB}$ & $0<\left|\rho_{c}\right|^{2}<0.1$ & $\approx 8.7 \mathrm{~dB}$ \\
\hline
\end{tabular}


Table 2. Results from measurements on prototype 2 with simulated head and hand.

\begin{tabular}{|l|l|l|l|l|}
\hline & MEG Ant. 1 & MEG Ant. 2 & Correlation & Diversity Gain \\
\hline Urban & $-10.3 \mathrm{~dB}$ & $-12.2 \mathrm{~dB}$ & $0.1<\left|\rho_{c}\right|^{2}<0.2$ & $\approx 9.1 \mathrm{~dB}$ \\
\hline Indoor & $-8.0 \mathrm{~dB}$ & $-10.5 \mathrm{~dB}$ & $0.15<\left|\rho_{c}\right|^{2}<0.25$ & $\approx 8.6 \mathrm{~dB}$ \\
\hline Isotropic & $-8.2 \mathrm{~dB}$ & $-11.0 \mathrm{~dB}$ & $0.15<\left|\rho_{c}\right|^{2}<0.25$ & $\approx 8.5 \mathrm{~dB}$ \\
\hline
\end{tabular}

Results and Discussion: The results from measurements and the diversity calculations performed on the prototypes are presented in Tables 1 (prototype 1 with simulated head) and 2 (prototype 2 with simulated head and hand).

Both prototype antenna systems produce signals that are uncorrelated to a very high degree. This may seem surprising since the antennas are very closely space. A possible explanation is that the antennas have different radiation patterns, so that the diversity systems mainly use angle diversity.

The mean effective gain, MEG, is, however, dramatically reduced for all antennas because of the simulated head. A further problem is that the MEG seems to differ between the antenna elements on the terminal with about $3 \mathrm{~dB}$. This effect may reduce the diversity gain to some extent. $[1,6]$

The fact that the head changes the radiation patterns makes it difficult to estimate the diversity performance of a prototype without measuring. An important conclusion of this study is that radiation patterns have to be measured with a simulated head in order to make a correct estimation of the diversity performance.

\section{References:}

[1] Schwartz M., Bennet W. R. and Stein S., "Communication Systems and Techniques" McGraw-Hill, New York 1966.

[2] Beckman C., Wahlberg U., “Antenna Systems for Polarization Diversity”, Technical note, Microwave Journal, Vol.40, 5, 330-334, May 1997.

[3] Pedersen G. F., Andersen J.B \& Skjaerris S., "Integrated handset antenna with low absorption and handset antenna diversity" Conference paper from IEE 20. January 1997. Reference no. 1997/022

[4] Ogawa K., Uwano T., " Diversity Antenna for Very Small 800-MHz Band Portable Telephones". IEEE Trans. On Antennas and Propagation, pp. 1342-1345, Vol. 42, no. 9. September 1994

[5] Ahlin L., Zander J., "Digital radiokommunikation - system och metoder" Studentlitteratur, Lund, Sweden, 1992.

[6] Vaughan R. \& Andersen J. B., "Antenna Diversity in Mobile Communications", IEEE Trans. On Vehicular Tech., vol. VT-36, no. 4, pp. 149- 172, November 1987. 